\title{
Long-term safety, efficacy, and patient acceptability of the intrauterine Copper T-380A contraceptive device
}

This article was published in the following Dove Press journal:

International Journal of Women's Health

30 June 2010

Number of times this article has been viewed

\author{
Bliss Kaneshiro \\ Tod Aeby \\ Department of Obstetrics and \\ Gynecology, John A Burns School \\ of Medicine, University of Hawaii, \\ Honolulu, Hawaii, USA
}

\begin{abstract}
The intrauterine device (IUD), primarily in the form of the copper IUD, is used by more than 150 million women around the world, making it the most widely used reversible method of contraception. With a remarkably low failure rate of less than 1 per 100 women in the first year of use, the Copper T-380A is in the top tier of contraceptives in terms of efficacy. Risks of utilization include perforation and an increased risk of infection in the first 20 days following insertion. Overall, the number of adverse events is low, making the Copper T-380A a very safe contraceptive method. The most common reasons for the discontinuation of this method are menstrual bleeding and dysmenorrhea. However, cumulative discontinuation rates of Copper T-380A are lower than that have been reported for other methods, indicating that the Copper T-380A is highly acceptable to women. After 5 years, approximately $50 \%$ of all women, who have a Copper T-380A inserted, will continue to use this highly effective contraceptive method.
\end{abstract}

Keywords: contraception, perforation, expulsion, pelvic inflammatory disease, continuation

\section{Introduction}

The placement of contraceptive devices in the uterus for the purpose of preventing pregnancy was first described in the scientific literature in the early 1900s. The original intrauterine devices (IUDs) were composed of contraceptive rings made out of a variety of materials, ranging from steel to silkworm gut. ${ }^{1-4}$ However, in the pre-World War II era, birth control was not only unpopular, it was considered criminal in many countries and led to the arrest of some of the originators of the IUD, including Dr Grafenberg, Germany, and Dr Ota, Japan. ${ }^{3,5}$

In the 1960s, the IUD was reinvented, primarily in the form of inert, plastic IUDs that are available in a wide variety of shapes and sizes including the Lippes Loop, Margulies Spiral, and Saf-T-Coil. ${ }^{6}$ In the 1970s, it was discovered that the addition of copper to the plastic device improved contraceptive efficacy, thereby allowing it to be made smaller, which improved the ease of insertion and decreased some of its untoward side effects. ${ }^{6}$ Of note, use of IUD plummeted in the mid-1970s and mid-1980s when 1 specific IUD, the Dalkon Shield (A.H. Robins Co., Richmond, VA, USA) ${ }^{\circledR}$, was linked to septic abortion and pelvic inflammatory disease. ${ }^{6}$

Today, 2 types of IUDs, containing either copper or progestin, have reemerged as effective, safe, and acceptable methods of contraception. Utilized by more than 150 million women worldwide, primarily in the form of the copper IUD, these devices are the most commonly used method of reversible contraception and are second only to female sterilization as the most common form of birth control overall. ${ }^{1,7}$
Correspondence: Bliss Kaneshiro I319 Punahou Ste, 824, Honolulu, HI 96826, USA

Tel + I 8082036500

Fax +I 8089552174

Email bkaneshiro@ucera.org 
All together, $13.6 \%$ of couples around the world have selected the IUD for birth control. Utilization rates are not homogenous from country to country. IUD use is high (14.5\%) in less developed countries and low (7.6\%) in more developed countries. ${ }^{7}$ Beyond socioeconomic status, rates of IUD use also vary on a geographic basis. Central and East Asian countries along with Latin American countries report that more than $70 \%$ of women, who use any form of contraception, use IUD. ${ }^{7}$ In contrast, in Western Europe, approximately $11 \%$ of women use IUD, whereas in most parts of Africa, less than $1 \%$ of women use IUD. ${ }^{7}$ In the United States, utilization of the IUD has been low since the 1980 s with only $2.1 \%$ of contracepting women reported IUD use. ${ }^{8}$

Copper IUDs are typically T-shaped or are composed of frameless devices that are anchored to the myometrium at the uterine fundus. ${ }^{9}$ The Copper T-380A, named for the $380 \mathrm{~mm}^{2}$ of copper surface area, is the most widely used IUD worldwide. ${ }^{1}$ The Copper T-380A has a plastic T-shaped core with copper placed around the vertical stem and horizontal arms. A silver core within the copper sheath is included to prevent fragmentation of the copper, extending the life span of the Copper T-380A past some of the older copper IUDs.

A higher surface area of copper results in higher contraceptive efficacy. Compared with older copper IUDs, which typically had less than $350 \mathrm{~mm}^{2}$ of copper surface area, the Copper T-380A has been able to achieve superior contraception while maintaining a similar side-effect profile. ${ }^{9-11}$ Like many of the IUDs, the frame of the Copper T-380A is connected to a monofilament thread that protrudes through the cervical canal into the upper vagina. This facilitates easy removal and allows the user to ensure that the IUD remains in the uterus.

\section{Mechanism of action}

The primary mechanism of action of the copper IUD is the prevention of fertilization through a cytotoxic inflammatory reaction that is spermicidal. ${ }^{12}$ In copper IUD users, the copper concentration in cervical mucus is substantial and leads to an inhibition of sperm motility. ${ }^{13}$ Because copper ions also result in significant endometrial changes, sperm migration, quality, and viability at the level of the endometrium is hindered. This effect is believed to be the primary mechanism by which the copper IUD provides contraception. ${ }^{14}$ Several investigators have attempted to recover spermatozoa from the fallopian tubes of women using an IUD and from control subjects not using an IUD. Spermatozoa recovery techniques varied between studies and sometimes were not reported in adequate detail to allow for duplication. Nonetheless, after both groups were inseminated, dramatically reduced numbers of spermatozoa were recovered from the ampullary portion of fallopian tubes in women using a copper IUD in situ. ${ }^{13,15-17}$

There is evidence to suggest that the copper IUD also works by impairing implantation. Investigators exploring biochemical evidence of fertilization in copper IUD users have measured 2 indicators of fertilization, early pregnancy factor (EPF) and human chorionic gonadotropin (hCG). EPF and hCG have been detected in a limited number of copper IUD users $(<1 \%){ }^{13,18-20}$ It is important to note that many of these studies used earlier generation copper IUDs with a copper content lower than that in the Copper T-380A. Also, the assays may have been affected by cross reactivity with hormonal markers. There is also indirect clinical evidence that the copper IUD has postfertilization contraceptive effects. Placing a copper IUD, even in the early luteal phase, is a highly effective emergency contraceptive. ${ }^{21}$

\section{Efficacy}

Several investigators have examined the efficacy of various copper IUD devices. A Cochrane review published by Kulier et $\mathrm{al}^{10}$ in 2007 examined 35 randomized controlled trials that all together included more than 50,000 women and made 16 different comparisons of efficacy from the scientific literature. The authors concluded that the Copper T-380A was more effective in preventing pregnancy than the other devices including the Multiload 375, Multiload 250, Copper T-220, and Copper T-200.

Although Copper T-380A is approved for use in the United States for 10 years and is licensed for use in the United Kingdom for 8 years, it has been shown to consistently maintain its efficacy for 12 years. ${ }^{22}$ Most failures will occur in the first year after insertion. Still, the annual pregnancy rate, including both intrauterine and ectopic pregnancies, for the first year of use is quite low, between 0.5 and 1.0 per 100 women. ${ }^{10,22,23}$ The published cumulative pregnancy rate for the remaining contraceptive life span of the Copper T-380A has been consistently very low. An interim analysis of an ongoing, large, multinational study reported a total pregnancy rate of 1.7 per 100 women for the first 3 years of use. ${ }^{24}$ Other large studies have reported the cumulative pregnancy rate of 1.5 per 100 women for the first 7 years of use..$^{22,25}$ The cumulative pregnancy rate appears to be extremely low after the seventh year. Pooled data from 2 large studies $(n=4,932)$ demonstrated no pregnancies after the eighth year of use..$^{22,25}$ After 12 years of use, a large multinational study conducted by the World Health Organization reported that the cumulative pregnancy rate for the Copper T-380A was 2.2 per 100 women..$^{22,25}$ 
Considering pregnancy prevention, the high efficacy of the Copper T-380A places it in the top tier of contraceptive methods and makes it comparable to the 10 -year pregnancy rate of 1.9 per 100 women that has been reported in women who have undergone surgical sterilization. ${ }^{26}$ There are also some small studies that have suggested that the Copper T-380A can be used beyond 12 years. A study conducted by Bahamondes et $\mathrm{al}^{27}$ in Brazil, followed a small group of women using Copper T-380A for contraception for a total of 16 years. Although the majority of women who had used the Copper T-380A for 10 years chose to discontinue it after they were informed it was only approved for use for 10 years, $45 \%$ of subjects were still using the Copper T-380A at 12 years with no reported pregnancies. After 16 years of use, there were still no reported pregnancies; although by this time, nearly $80 \%$ of subjects had stopped using the Copper $\mathrm{T}-380 \mathrm{~A}$. The mean age of the study population at the 10 -year mark was 38.4 years. A study conducted by the Population Council followed women using the Copper T-380A through 20 years. The small number of subjects contributed a total of 70 woman-years of observation between 15 and 20 years, and during this time period, no women became pregnant. ${ }^{28}$ In both studies, the reported high contraceptive efficacy may have been related to the fact that women who have used an IUD for more than 12 years are typically older, with decreased fertility rates. Although adequate data is clearly lacking, the authors of these studies hypothesized that women as young as 25 could potentially use a Copper T-380A for contraception until menopause. ${ }^{28}$

\section{Contraceptive failure with the Copper T-380A}

Several studies have demonstrated that younger women are more likely to experience contraceptive failure with a copper IUD than older women..$^{29}$ However, it should be noted that the copper IUD is still more efficacious than other contraceptive methods in this age group. In particular to the Copper T-380A, a nested case-control study of women using various forms of a copper IUD showed that young age was a significant risk factor for experiencing a contraceptive failure. ${ }^{30}$ Because various copper IUDs were used, statistical adjustment was made for copper surface area (copper surface area of less than $350 \mathrm{~mm}^{2}$ significantly increased the likelihood of contraceptive failure). Compared with women younger than 25 years of age, women older than 35 years were significantly less likely to experience a failure (odds ratio $[\mathrm{OR}]=0.2 ; 95 \% \mathrm{CI}$, 0.1-0.7). The odds of experiencing a contraceptive failure with the Copper T-380A at 40 years or more compared with women younger than 25 years was even lower $(\mathrm{OR}=0.0$; 95\% CI, 0.0-0.3). In several studies, parity, uterine position, and uterine size were not associated with an increased risk of contraceptive failure. ${ }^{31,32}$ However, suboptimal placement of the IUD within the cervix increased the likelihood of contraceptive failure. ${ }^{14,33}$ If an IUD is placed in the cervix, the likelihood of contraceptive failure was significantly increased ( $\mathrm{OR}=13.93 ;$; 95\% CI, 4.13-48.96).

Although it has been hypothesized that anti-inflammatory medications, including aspirin, and other nonsteroidal anti-inflammatory medications could increase the risk of contraceptive failure with an IUD, there is no scientific evidence on this. A case-control study published in 2006 found no differences in the types of medications taken among women who had a confirmed pregnancy with an IUD in place and those who did not. ${ }^{34}$ Another case-control study published in 1989 found that aspirin use was associated with contraceptive failure with a copper IUD. ${ }^{35}$. However, in this study, the same relationship was not confirmed for other anti-inflammatory medications, leading investigators to question the validity of the association.

The overall risk of ectopic pregnancy is decreased in women using a Copper T-380A. Rates of ectopic pregnancy in women who do not use contraceptives are reported to be between 3.00 and 4.50 per 1,000 woman-years, whereas rates of ectopic pregnancy in women using a Copper T-380A are reported to be 0.20 per 1,000 woman-years. ${ }^{36,37}$ Thus, the IUD is protective against ectopic pregnancy, making women who use the Copper T-380A likely to have an ectopic pregnancy $90 \%$ less than women using no contraceptives. ${ }^{36}$ As a consequence, a prior history of an ectopic pregnancy is not a contraindication to IUD use. In patients with a history of prior ectopic, an IUD would be a better choice than no contraception or a less reliable method. In addition, previous use of an IUD does not increase a woman's risk of an ectopic pregnancy. ${ }^{38-40}$ However, if a pregnancy occurs with an IUD in place, there is a relatively high ratio of ectopic to intrauterine pregnancies, with approximately $6 \%$ of pregnancies among copper IUD users being ectopic. ${ }^{36}$

If an intrauterine pregnancy does occur with an IUD in situ, the spontaneous abortion rate is estimated to be $40 \%-50 \%{ }^{41}$ If the woman wishes to continue the pregnancy and the strings are visible, removal should be attempted if it can be done without placing instruments in the uterus. If the IUD is successfully removed, the rate of spontaneous abortion is lowered to $20 \%{ }^{41}$ There is no evidence of an increased risk of teratogenesis to infants born to women with an IUD in situ. ${ }^{42}$ 


\section{Safety}

Effective methods of contraception, such as the Copper T-380A, have allowed many women around the world to avoid the health risks of unwanted pregnancy and have provided for the spacing of pregnancies. This has contributed to improvements in infant and child survival. There are only a handful of adverse events that accompany the Copper T-380A use including perforation, expulsion, and infection. These infrequent events should always be viewed in perspective with the multiple health benefits associated with the ability to plan fertility.

\section{IUD-associated adverse events}

Perforation of the uterus occurs at the time of IUD insertion at a rate of $1-2$ per 1,000 insertions. ${ }^{43,44} \mathrm{~A}$ study that included more than 21,000 insertions through pooled data from multiple international studies estimated the rate of perforation to be 1.5 per 1,000 insertions for the Copper T-380A.${ }^{43}$ Factors associated with an increased risk of perforation include skill of the clinician and anatomic factors, such as a stenotic cervix or an immobile or a retroverted uterus. ${ }^{43}$ Of note, no particular IUD has been found to be easier to insert or more likely to perforate than the others. ${ }^{9}$

Most perforations are not recognized at the time of insertion and are discovered when there is a shortening or disappearance of the IUD strings or when the patients present with pregnancy. Although serious complications due to a perforated IUD are rare, it is generally recommended that the copper IUDs to be retrieved as soon as possible. Copper ions are inflammatory, and there are multiple case reports of intra-abdominal copper IUDs eroding into the bladder or the gastrointestinal tract, typically the small bowel. ${ }^{45}$

Comparative randomized clinical trials have reported expulsion rates to be lower with the Copper T-380A than with other copper IUDs. Expulsion is most likely to occur in the first year after insertion and can occur at any time during the 10-year period of use. ${ }^{44}$ In a large study of 427 women, there were no expulsions reported after the first year of use. This finding is somewhat atypical as most studies have found a small number of IUD expulsions continue to occur after the first year of use. Reported cumulative expulsion rates are $2.4 \%-6.0 \%$ for the first year of use, $3.4 \%-6.7 \%$ at 2 years, $4.4 \%-5.4 \%$ at 3 years, and $11.2 \%$ at 10 years. ${ }^{44,46-49}$ Expulsion tends to occur at the time of menstruation and is often associated with cramping, vaginal discharge, and bleeding. If a partially expelled IUD is noted on physical examination, it should be removed and replaced as long as there are no signs of pregnancy or infection. The only factors that have been consistently associated with a higher rate of expulsion are age younger than 20 years and nulliparity. ${ }^{5,44,47}$
A study by Mishell et al ${ }^{50}$ published in 1966 demonstrated that the uterus is routinely contaminated with bacteria at the time of IUD insertion. Since that, one of the primary concerns with IUD utilization has been the risk of upper genital tract infection and the concern that an in situ IUD could result in an ongoing risk of pelvic inflammatory disease. However, large studies performed in a variety of clinical settings and geographic locations have demonstrated that the insertion process rather than the in situ IUD increases the risk of infection. ${ }^{51}$ Even at the time of insertion, the increased risk of infection remains in an acceptably low range. In a review of data from 12 clinical trials conducted by the World Health Organization that included nearly 23,000 IUD insertions, the rate of pelvic inflammatory disease was 9.68 per 1,000 woman-years in the first 20 days after insertion and 1.39 per 1,000 woman-years thereafter. ${ }^{51}$ In total, pelvic inflammatory disease was identified in 1.6 cases per 1,000 woman-years for the whole duration of use. Although the risk of pelvic inflammatory disease was more than 6 times higher in the first 20 days after insertion (relative risk $[R R]=6.30 ; 95 \%$ CI, 3.42-11.6), it decreased to a rate similar to reproductiveaged women who were not using an IUD for contraception in subsequent years. ${ }^{51}$

The logical question of the utility of antibiotic prophylaxis at the time of insertion was addressed in a Cochrane review by Grimes et al in $2001 .^{52}$ The 4 randomized clinical trials, addressing antibiotic prophylaxis at the time of IUD insertion, showed that doxycycline or azithromycin administered at the time of insertion does not decrease the risk of upper genital tract infection ( $R R=0.9 ; 95 \%$ CI, $0.5-1.5) .{ }^{52}$ Although antibiotics did result in a small reduction in unscheduled visits following IUD insertion ( $\mathrm{RR}=0.8 ; 95 \% \mathrm{CI}, 0.7-1.0$ ), it did not decrease the likelihood of removal within 90 days ( $R R=1.1 ; 95 \%$ CI, 0.7-1.6). Of note, based on a study performed in a geographic locale with a high prevalence of sexually transmitted diseases, Grimes et al concluded that prophylaxis might be warranted for women living in similar high-risk regions. ${ }^{53}$

\section{Relevant contraindications}

Because product labeling and practice guidelines can vary from country to country, many experts have highlighted the importance of incorporating relevant contraindications when considering the utilization of the Copper T-380A. ${ }^{54}$ Because the copper IUDs are completely nonhormonal, they can be used safely in women who have contraindications to exogenous estrogen and progestins, including women with active liver disease and women at risk for venous thromboembolism. 
Absolute evidence-based contraindications are few in number. With the Copper T-380A, there are 5 distinct categories of contraindications: infection, pregnancy, uterine factors, gynecologic cancer, and adverse reactions to copper.

It is estimated that uterine anomalies occur in approximately $4 \%$ of reproductive-aged women. ${ }^{55}$ Severe uterine distortion and anomalies, like cervical stenosis, large fibroids, or a uterine septum, can make insertion more difficult and may increase the risk of expulsion. However, if the uterine cavity can be safely entered and it does not appear to be distorted, the Copper T-380A can be placed. ${ }^{56}$ Identification of pregnancy is an obvious contraindication to the use of a Copper T-380A device. Although there is no direct evidence of harm in using a copper IUD in women with Wilson's disease, it would seem prudent to seek other contraceptive methods because these women are unable to metabolize copper.

In terms of gynecologic cancer and unexplained, abnormal uterine bleeding suspicious for cancer, evaluation would ideally begin prior to IUD placement. Because some gynecologic malignancies present with irregular and heavy bleeding, placement of a copper IUD in women with these symptoms may delay diagnosis and worsen bleeding patterns. However, as in all areas of medicine, risk and benefit must be considered, and this caution should be weighed against the need to provide effective contraception. In some low-resource settings, timely diagnosis and treatment of gynecologic cancers are not possible, and if the likelihood of pregnancy is high, the benefit of preventing pregnancy in a woman, who may have cancer, may outweigh the potential risks associated with the placement of the IUD.

Concern about the risk of pelvic inflammatory disease has long hindered the use of the IUD. IUD insertion is generally contraindicated if an active cervical infection is identified. This is based on indirect rather than direct evidence. A systematic review of the literature published in 2006 did not identify any comparative studies of contraceptive insertion in the presence of a cervical infection versus no infection. ${ }^{57}$ However, there is indirect evidence from 6 prospective studies, in which an IUD was inadvertently placed in the presence of a sexually transmitted cervical infection. An analysis of these studies suggests that even in the presence of these infections, the risk of pelvic inflammatory disease is still low. In women who had negative cervical cultures, the risk of pelvic inflammatory disease with IUD placement was $0 \%-2 \%$, whereas in the presence of infection, it was $0 \%-5 \%{ }^{57}$ Again, a reasonable assessment of the risks and benefits should be weighed because areas with high rates of unintended pregnancy may have high rates of sexually transmitted infection and may lack laboratory facilities to test for infection.

\section{Acceptability}

Many aspects of the Copper T-380A make it an ideal contraceptive method for many women. In addition to providing long-lasting, highly effective contraception, it does not interfere with sexual intercourse, does not interact with medications, is immediately reversible, and is not subject to forgetfulness or changes in medical supply. Moreover, the IUD does not have any hormone-related side effects or contraindications, and it does not affect breastfeeding. There is also no evidence to suggest that the copper IUD is associated with weight gain, altered libido, or mood changes. ${ }^{58,59}$

However, with all types of copper IUDs, periods can become longer and heavier, and there is an increased likelihood of dysmenorrhea. ${ }^{14}$ Menstrual blood loss increases by approximately $50 \%$ and the increase persists for the duration of IUD use. ${ }^{60}$ Although this increase in blood loss typically does not cause clinically significant anemia, depletion of iron stores, as evidenced by serum ferritin levels, is seen after more than 1 year of use. ${ }^{61}$

Consequently, bleeding and dysmenorrhea are the most frequent reasons for copper IUD discontinuation. In the first year of use, between $4 \%$ and $15 \%$ of women using a Copper T-380A will have it removed for these reasons. ${ }^{5,24,62}$ In a multinational study $(n=427)$ that included the United States and the European countries, 13.8 per 100 women using the Copper T-380A discontinued the IUD over the course of the first year, with 6.9 per 100 women discontinuing because of pain or bleeding. ${ }^{63}$ In another multinational study $(n=441)$ that was conducted in Yugoslavia and Panama, the discontinuation rate was 10 per 100 women, with 5 per 100 women discontinuing because of pain and bleeding. ${ }^{48}$ Other reasons for IUD discontinuation included infection and a desire for fertility. ${ }^{64}$ Although the discontinuation rate of the Copper T-380A is significant, it is important to note that 1 -year continuation rates are higher than that has been reported with other methods. For example, in the United States, after 1 year, $78 \%$ of women will continue to use the Copper T-380A compared with $68 \%$ of women who were given oral contraceptive pills and $56 \%$ of women who received injectable contraception. ${ }^{65}$

In subsequent years, cumulative discontinuation rates continue to increase to $22 \%-33 \%$ after 3 years, $60 \%$ after 5 years, and between $60 \%$ and $72 \%$ after 10 years of use. $44,48,66-68$ In general, approximately $50 \%$ of all patients who have a Copper T-380A will discontinue it within 5 years. Conversely, after 5 years, approximately $50 \%$ of all patients will still be using this reliable and effective form of contraception.

Because bleeding and pain are the primary reasons, some women chose to have their IUDs removed, and several 
investigators have focused on the treatment of these side effects. A Cochrane review analyzed 15 randomized controlled trials that included more than 2,700 women, from 10 countries, who used nonsteroidal anti-inflammatory drugs (NSAIDS) to decrease pain and bleeding with a copper IUD. ${ }^{69}$ All NSAIDS, including naproxen, sprofen, mefenamic acid, ibuprofen, indomethacin, flufenamic acid, alcolofenac, and diclofenac, reduced pain and bleeding in women who complained of these symptoms. However, prophylactic administration of NSAIDs after insertion did not decrease complaints of pain or bleeding or increase continuation rates. ${ }^{62}$

Small alterations to the Copper T-380A have also not made a significant difference in side effects. The Copper 380 Slimline (TCu380S) differs from the Copper 380A in that the copper sleeves cover the lateral ends of the horizontal arms rather than encircling the middle of the arms. However, this modification failed to change the rates of bleeding, pain, or discontinuation and also did not change the efficacy of the device. ${ }^{10}$

\section{Special groups}

\section{Nulliparous women}

The length, width, and volume of the uterine cavity of nulligravid women tends to be smaller than the cavity of gravid women. ${ }^{70}$ This led to initial concerns that the Copper T-380A may be too large to use in nulliparous women. Although most experts advocate for the utilization of IUDs in women who have never had a child, a Cochrane review published in 2006 addressing this topic noted that there were relatively few studies in the medical literature and concluded that the optimum device for nulliparous women has yet to be established. ${ }^{71}$ A smaller version of the Copper T-380A, the Copper T-380Nul, which is similar in shape and in copper content but is smaller in length and width, is manufactured and used in Mexico.

A randomized controlled trial that included 1,170 nulliparous women using the standard Copper T-380A, the Copper T-380Nul, and the Multilaod Copper 375sl demonstrated lower expulsion rates $(3.3 \%$ vs $1.8 \%, P<0.001)$ and higher continuation rates $(85.4 \%$ vs $29.5 \%, P<0.001)$ in nulliparous women with the Copper T-380Nul compared with the traditional Copper T380A while maintaining comparable efficacy. ${ }^{72}$ As in parous women, most removals were performed because of bleeding and pain. It is notable that in this particular study, the continuation rate of the Copper T-380A in nulliparous women was quite low at $29.5 \%( \pm 12.9)$ at 1 year. Another study of the Copper T-380A in nulliparous women reported a expulsion rate of $6 \%$ and a removal rate of $14 \%$ in the first year. ${ }^{32}$
With all women, particularly with nulliparous women, future fertility is an important issue. After cessation of the use of a copper IUD, return of fertility is rapid. ${ }^{73}$ In a study by Doll et $\mathrm{a}^{74}$ return to fertility within 1 year was no different in women using a barrier method, a copper IUD or oral contraceptive pills. In a case - control study published by Hubacher et $\mathrm{a}^{75}$ previous use of a copper IUD was not a risk factor for infertility although the presence of chlamydial antibodies in both previous users and nonusers of the IUD was a risk factor for infertility. The risk of tubal occlusion following the use of the copper IUD is compared to the risk with other contraceptive methods in Figure 1. Thus, in the absence of other contraindications, a concern about future fertility should not be a deterrent to copper IUD use in nulliparous women.

\section{Adolescents}

Expert opinion also suggests that the Copper T-380A can be used in adolescents. However, there are little data regarding safety, efficacy, and acceptability of IUDs in this population. ${ }^{76}$ A systematic review published by Deans et al ${ }^{77}$ identified 6 cohort and 7 case series reports addressing IUD use in adolescents. However, none included the Copper T-380A. There is 1 pilot study $(n=23)$ that was published in 2010 that was conducted in the United States where adolescents were randomized to a levonorgestrel IUD or a Copper T-380A. ${ }^{78}$ After 6 months, only $45 \%$ of adolescents who received the Copper T-380A were still using it. Of the 11 subjects, who received a Copper T-380A, 2 experienced a partial expulsion, 1 had removed it at the time of spontaneous abortion, and 4 requested removal because of pain and bleeding.

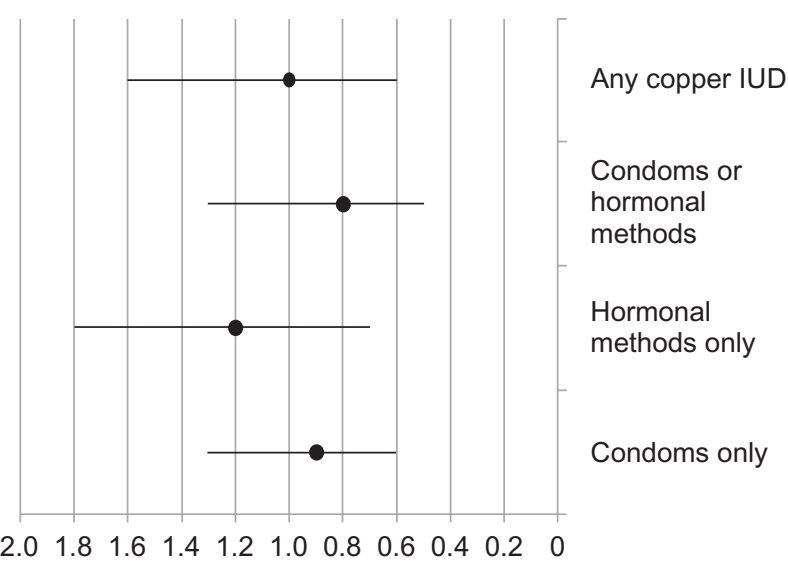

Figure I Previous use of contraceptives and risk of tubal occlusion presented as odds ratios and $95 \%$ Confidence Intervals.

Note: Women with no previous use of contraception, rhythm method or withdrawal comprised the reference group. Hormonal methods only included oral contraceptives or injectables. From data of Hubacher et al 2001.75 
With this paucity of data, it is difficult to comment on the use of the Copper T-380A in adolescents. However, this should be countered with the pressing need to prevent unintended pregnancy in this group of women. Young age and associated high fertility is likely to confer a higher risk of pregnancy in young women compared with older women using the Copper T-380A. However, the contraceptive efficacy of the Copper T-380A is still likely to be higher than that with other methods. ${ }^{36}$ Although women younger than 20 years are more likely to request IUD removal because of pain and bleeding and are more likely to experience an expulsion. Discontinuation rates of all types of contraceptives in this age group is higher than that in adult women. ${ }^{79,80}$ Of note, there is no evidence to suggest that rates of infection associated with IUD insertion are higher in adolescents than in adults.

\section{Emergency contraception}

Emergency contraception prevents pregnancy after unprotected intercourse has occurred. Unlike hormonal emergency contraceptives, the copper IUD works by preventing implantation and can be inserted up to 120 hours after unprotected intercourse. ${ }^{81}$ Utilization of the Copper IUD as an emergency contraceptive has the added benefit of providing long-term, highly effective contraception in a group at risk for unintended pregnancy. However, in most places, the Copper T-380A is underutilized for this purpose.

Recommendations regarding the use of a copper IUD as an emergency contraceptive are based on observational studies conducted in China. In a study of almost 2,000 women, insertion of the Copper T-380A within 120 hours after unprotected intercourse resulted in only 2 pregnancies $(0.13 \%)$ over the course of a year. ${ }^{82}$ A meta-analysis, which included multiple types of copper IUDs, reported only 1 pregnancy in 879 women who used a copper IUD after unprotected intercourse and estimated the pregnancy rate with postcoital IUD insertion to be $0.1 \%$. A pregnancy rate much lower than the $1.5 \%$ quoted for a single dose of levonorgestrel..$^{83,84}$

\section{Postabortion and postpartum insertion}

In many ways, insertion of IUDs in the postabortion and postpartum setting is ideal. Women are highly motivated to use contraception at this time and are often in a health care setting with clinicians capable of inserting the devices. ${ }^{85}$ A Cochrane review on this topic identified 9 appropriately described randomized studies addressing postabortion insertion. ${ }^{85}$ Perforations and infections were rare despite pregnancy-related changes, and the risk of these events was similar to those reported for delayed insertion. ${ }^{51,53,87,88}$ However, none of the studies described in the Cochrane review used the Copper T-380A device. ${ }^{86}$ Only 1 study directly compared immediate vs delayed insertion of a Copper 7 IUD, and there was a nonsignificant increase in the risk of expulsion with immediate postabortion insertion $(\mathrm{RR}=5.69$, $95 \%$ CI $0.75,43.08) .{ }^{89}$ In this randomized study, it is important to note that $42 \%$ of women randomized to delayed insertion group did not return for insertion. A benefit that likely counters the probable increased risk of expulsion.

A systematic review addressed insertion of IUDs in the postpartum period. ${ }^{90}$ Although the studies identified in this review were of poor to fair methodological quality and risk estimates varied considerably between studies, there were some consistent conclusions. Rates of adverse events, such as infection and perforation, were low. In terms of expulsion, insertion within 10 minutes of placental delivery led to lower expulsion rates than when insertion took place between 10 minutes and 72 hours. ${ }^{90}$ In a prospective cohort study, $36.9 \%$ of Copper T-380A IUDs were expulsed when placed less than 10 minutes after placental delivery compared with $69.8 \%$ in the later postpartum period and $6.9 \%$ in the 6-week postpartum group $(P<0.003) .{ }^{91}$ Another study using the Copper T-380A and the multiload copper 375 inserted less than 10 minutes after delivery of the placenta reported an expulsion rate of $9 \%$ after cesarean section and $13 \%$ after vaginal delivery. After 1 year, $16 \%$ of women in the cesarean section group and $6 \%$ of women in the vaginal delivery group requested IUD removal. ${ }^{92}$ Finally, the addition of a chromic suture to anchor the IUD has not been shown to decrease the risk of expulsion and hand insertion is comparable to insertion with a sponge forcep, so either technique can be used. ${ }^{93}$

\section{Summary}

The Copper T-380A is an extremely effective, safe, long lasting, rapidly reversible method of contraception that does not interfere with intercourse, is not subject to forgetfulness, and once inserted, is not subject to changes in medical supply or access to health care. It is also nonhormonal, so it does not have any hormone-related side effects or contraindications and does not affect breastfeeding. These aspects have contributed to its popularity worldwide.

As described in this review, there are downsides to the utilization of the Copper T-380A. It requires a trained clinician to insert, and its use is associated with increased menstrual bleeding and pain. These side effects can lead to discontinuation 
of this method. There are also some adverse events associated with IUD use, including perforation and an increased infection immediately following insertion. However, rates of these complications are remarkably low and are easily countered by the health benefits women and their families experience from the prevention of unintended pregnancy.

\section{Disclosures}

The authors report no conflicts of interest in this work.

\section{References}

1. d'Arcangues C. Worldwide use of intrauterine devices for contraception. Contraception. 2007;75:S2-S7.

2. Fischer W. 50-year record of scientifically founded use of IUD - in memorian Ernst Grafenberg (author's transl). Zentralbl Gynakol. 1979;101:929-932.

3. Burnhill MS. The rise and fall and rise of the IUD. Am J Gynecol Health. 1989;3:6-10.

4. Ota T. A study on the birth control with an intrauterine instrument. Jpn J Obstet Gynecol. 1934;17:210-214.

5. Speroff L, Darney PD. A Clinical Guide for Contraception. 4th ed. Philadelphia: Lippincott Williams and Wilkins; 2005.

6. Cheng D. The intrauterine device: still misunderstood after all these years. South Med J. 2000;93:859-864.

7. World Contraceptive Use 2005. New York: United Nations, Population Division; [cited 2010 Jan 21]. Available from: http://www. un.org/esa/population/publications/contraceptive2005/WCU2005. htm. Accessed Jan 21, 2010.

8. Chandra A, Martinez GM, Mosher WD, Abma JC, Jones J. Fertility, family planning, and reproductive health of US women: data from the 2002 National Survey of Family Growth. Vital Health Stat 23. 2005; $1-160$.

9. O'Brien PA, Kulier R, Helmerhorst FM, Usher-Patel M, d'Arcangues C. Copper-containing, framed intrauterine devices for contraception: a systematic review of randomized controlled trials. Contraception. 2008;77:318-327.

10. Kulier R, O’Brien PA, Helmerhorst FM, Usher-Patel M, D'Arcangues C. Copper containing, framed intra-uterine devices for contraception. Cochrane Database Syst Rev. 2007;CD005347.

11. Tatum HJ. Intrauterine contraception. Am J Obstet Gynecol. 1972;112:1000-1023.

12. Holland MK, White IG. Heavy metals and human spermatozoa. III. The toxicity of copper ions for spermatozoa. Contraception. 1988;38: 685-695.

13. Stanford JB, Mikolajczyk RT. Mechanisms of action of intrauterine devices: update and estimation of postfertilization effects. Am J Obstet Gynecol. 2002;187:1699-1708.

14. Mishell DR Jr. Intrauterine devices: mechanisms of action, safety, and efficacy. Contraception. 1998;58:45S-53S; quiz 70S.

15. Tredway DR, Umezaki CU, Mishell DR Jr, Settlage DS. Effect of intrauterine devices on sperm transport in the human being: preliminary report. Am J Obstet Gynecol. 1975;123:734-735.

16. Koch JU. Sperm migration in the human female genital tract with and without intrauterine devices. Acta Eur Fertil. 1980;11:33-60.

17. Aref I, Kandil O, El-tagi A, Morad MR. Effects of non-medicated and copper IUDs on sperm migration. Contracept Deliv Syst. 1983;4: 203-206.

18. Segal SJ, Alvarez-Sanchez F, Adejuwon CA, Brache de Mejia V, Leon P, Faundes A. Absence of chorionic gonadotropin in sera of women who use intrauterine devices. Fertil Steril. 1985;44:214-218.

19. Ylikorkala O, Siljander M, Huhtaniemi I, Kauppila A, Seppälä M. Trophoblastic markers in women using intrauterine contraception. Obstet Gynecol. 1980;55:329-332.
20. Wilcox AJ, Weinberg CR, Armstrong EG, Canfield RE. Urinary human chorionic gonadotropin among intrauterine device users: detection with a highly specific and sensitive assay. Fertil Steril. 1987;47: 265-269.

21. Cheng L, Gulmezoglu AM, Piaggio G, Ezcurra E, Van Look PF. Interventions for emergency contraception. Cochrane Database Syst Rev. 2008;CD001324.

22. Long-term reversible contraception. Twelve years of experience with the TCu380A and TCu220C. Contraception. 1997;56:341-352.

23. Meirik O, Rowe PJ, Peregoudov A, Piaggio G, Petzold M; for IUD Research Group at the UNDP/UNFPA/WHO/World Bank Special Programme of Research, Development and Research Training in Human Reproduction. The frameless copper IUD (GyneFix) and the TCu380A IUD: results of an 8-year multicenter randomized comparative trial. Contraception. 2009;80:133-141.

24. The TCu380A IUD and the frameless IUD "the FlexiGard": interim three-year data from an international multicenter trial: UNDP, UNFPA, and WHO Special Programme of Research, Development and Research Training in Human Reproduction, World Bank: IUD research group. Contraception. 1995;52:77-83.

25. WHO Special Programme of Research, Development and Research Training in Human Reproduction, Task Force on the Safety and Efficacy of Fertility Regulating Methods, The TCu 380A, TCu220C, Multiload 250, and Nova T IUDs at 3, 5 and 7 years of use. Contraception. 1990;42:141.

26. Peterson HB, Xia Z, Hughes JM, Wilcox LS, Tylor LR, Trussell J. The risk of pregnancy after tubal sterilization: findings from the US Collaborative Review of Sterilization. Am J Obstet Gynecol. 1996; 174:1161-1168; discussion 8-70.

27. Bahamondes L, Faundes A, Sobreira-Lima B, Lui-Filho JF, Pecci P, Matera S. TCu 380A IUD: a reversible permanent contraceptive method in women over 35 years of age. Contraception. 2005;72:337-341.

28. Sivin I. Utility and drawbacks of continuous use of a copper T IUD for 20 years. Contraception. 2007;75:S70-S75.

29. Allonen H, Luukkainen T, Nielsen NC, Nygren KG, Pyörälä T. Factors affecting the clinical performance of Nova T and Copper T 200. Obstet Gynecol. 1984;64:524-529.

30. Avecilla-Palau A, Moreno V. Uterine factors and risk of pregnancy in IUD users: a nested case-control study. Contraception. 2003;67:235-239.

31. Chi IC, Farr G, Dominik R, Robinson N. Do retroverted uteri adversely affect insertions and performance of IUDs? Contraception. 1990;41:495-506.

32. Sivin I, Stern J. Long-acting, more effective copper T IUDs: a summary of US experience, 1970-75. Stud Fam Plann. 1979;10:263-281.

33. Anteby E, Revel A, Ben-Chetrit A, Rosen B, Tadmor O, Yagel S. Intrauterine device failure: relation to its location within the uterine cavity. Obstet Gynecol. 1993;81:112-114.

34. Thonneau P, Almont T, de La Rochebrochard E, Maria B. Risk factors for IUD failure: results of a large multicentre case-control study. Hum Reprod. 2006;21:2612-2616.

35. Papiernik E, Rozenbaum H, Amblard P, Dephot N, de Mouzon J. Intrauterine device failure: relation with drug use. Eur J Obstet Gynecol Reprod Biol. 1989;32:205-212.

36. Sivin I. Dose- and age-dependent ectopic pregnancy risks with intrauterine contraception. Obstet Gynecol. 1991;78:291-298.

37. Skjeldestad FE. How effectively do copper intrauterine devices prevent ectopic pregnancy? Acta Obstet Gynecol Scand. 1997;76:684-690.

38. Wilson JC. A prospective New Zealand study of fertility after removal of copper intrauterine contraceptive devices for conception and because of complications: a four-year study. Am J Obstet Gynecol. 1989;160:391-396.

39. A multinational case-control study of ectopic pregnancy. The World Health Organization's Special Programme of Research, Development and Research Training in Human Reproduction: Task Force on Intrauterine Devices for Fertility Regulation. Clin Reprod Fertil. 1985;3:131-143. 
40. Marchbanks PA, Annegers JF, Coulam CB, et al. Risk factors for ectopic pregnancy. A population-based study. JAMA. 1988;259:1823-1827.

41. Alvior GT Jr. Pregnancy outcome with removal of intrauterine device Obstet Gynecol. 1973;41:894-896.

42. United Kingdom Family Planning Research Network, Pregnancy outcome associated with the use of IUDs. Br J Fam Plann. 1989;15:7.

43. Chi I, Feldblum PJ, Rogers SM. IUD - related uterine perforation: an epidemiologic analysis of a rare event using an international dataset. Contracept Deliv Syst. 1984;5:123-130.

44. A randomized multicentre trial of the Multiload 375 and TCu380A IUDs in parous women: three-year results. UNDP/UNFPA/WHO/World Bank, Special Programme of Research, Development and Research Training in Human Reproduction: IUD Research Group. Contraception. 1994;49:543-549.

45. Kaneshiro B, Jensen J, Edelman A. Copper T380A intrauterine device: lost and found. Hawaii Med J. 2008;67:131-132.

46. Arowojolu AO, Otolorin EO, Ladipo OA. Performances of copper T $380 \mathrm{~A}$ and multiload copper 375/250 intrauterine contraceptive devices in a comparative clinical trial. Afr J Med Sci. 1995;24:59-65.

47. Sastrawinata S, Farr G, Prihadi SM, et al. A comparative clinical trial of the TCu 380A, Lippes Loop D and Multiload Cu 375 IUDs in Indonesia. Contraception. 1991;44:141-154.

48. Champion CB, Behlilovic B, Arosemena JM, Randic L, Cole LP, Wilkens LR. A three-year evaluation of TCu $380 \mathrm{Ag}$ and multiload Cu 375 intrauterine devices. Contraception. 1988;38:631-639.

49. Cole LP, Potts DM, Aranda C, et al. An evaluation of the TCu $380 \mathrm{Ag}$ and the Multiload Cu375. Fertil Steril. 1985;43:214-217.

50. Mishell DR Jr, Bell JH, Good RG, Moyer DL. The intrauterine device: a bacteriologic study of the endometrial cavity. Am J Obstet Gynecol. 1966;96:119-126.

51. Farley TM, Rosenberg MJ, Rowe PJ, Chen JH, Meirik O. Intrauterine devices and pelvic inflammatory disease: an international perspective. Lancet. 1992;339:785-788.

52. Grimes DA, Schulz KF. Antibiotic prophylaxis for intrauterine contraceptive device insertion. Cochrane Database Syst Rev. 2001;CD001327.

53. Sinei SK, Schulz KF, Lamptey PR, et al. Preventing IUCD-related pelvic infection: the efficacy of prophylactic doxycycline at insertion Br J Obstet Gynaecol. 1990;97:412-419.

54. Nelson AL. Contraindications to IUD and IUS use. Contraception. 2007;75:S76-S81.

55. Raga F, Bauset C, Remohi J, Bonilla-Musoles F, Simón C, Pellicer A. Reproductive impact of congenital Mullerian anomalies. Hum Reprod. 1997;12:2277-2281

56. Medical Eligibility Criteria for Contraceptive Use. [cited 2008 Jan 30]. Available from: http://www.who.int/reproductive-health/publications/ mec/. Accessed Jan 30, 2010.

57. Mohllajee AP, Curtis KM, Peterson HB. Does insertion and use of an intrauterine device increase the risk of pelvic inflammatory disease among women with sexually transmitted infection? A systematic review. Contraception. 2006;73:145-153.

58. Andersson K, Odlind V, Rybo G. Levonorgestrel-releasing and copperreleasing (Nova T) IUDs during five years of use: a randomized comparative trial. Contraception. 1994;49:56-72.

59. Martin-Loeches M, Orti RM, Monfort M, Ortega E, Rius J. A comparative analysis of the modification of sexual desire of users of oral hormonal contraceptives and intrauterine contraceptive devices. Eur J Contracept Reprod Health Care. 2003;8:129-134.

60. Milsom I, Andersson K, Jonasson K, Lindstedt G, Rybo G. The influence of the Gyne-T 380S IUD on menstrual blood loss and iron status. Contraception. 1995;52:175-179.

61. Effects of contraceptives on hemoglobin and ferritin. Task Force for Epidemiological Research on Reproductive Health, United Nations Development Programme/United Nations Population Fund/World Health Organization/ World Bank Special Programme of Research, Development and Research Training in Human Reproduction, World Health Organization, Geneva, Switzerland. Contraception. 1998;58:262-273.
62. Hubacher D, Reyes V, Lillo S, et al. Preventing copper intrauterine device removals due to side effects among first-time users: randomized trial to study the effect of prophylactic ibuprofen. Hum Reprod. 2006;21: $1467-1472$.

63. Rosenberg MJ, Foldesy R, Mishell DR Jr, Speroff L, Waugh MS, Burkman R. Performance of the TCu380A and Cu-Fix IUDs in an international randomized trail. Contraception. 1996;53:197-203.

64. Long-acting reversible contraception the effective and appropriate use of long-acting reversible contraception. Regents Park, London: National Collaborating Centre for Women's and Children's Health Commissioned by the National Institute for Health and Clinical Excellence, 2005 October 2005. Report No.

65. Hatcher RA. Contraceptive Technology. 19th rev. ed. New York: Ardent Media; 2007.

66. Sivin I, Stern J, Coutinho E, et al. Prolonged intrauterine contraception: a seven-year randomized study of the levonorgestrel $20 \mathrm{mcg} / \mathrm{day}$ (LNg 20) and the Copper T380 Ag IUDS. Contraception. 1991;44:473-480.

67. Sivin I, Stern J. Health during prolonged use of levonorgestrel $20 \mathrm{micrograms} / \mathrm{d}$ and the copper TCu $380 \mathrm{Ag}$ intrauterine contraceptive devices: a multicenter study. International Committee for Contraception Research (ICCR). Fertil Steril. 1994;61:70-77.

68. Sivin I, el Mahgoub S, McCarthy T, et al. Long-term contraception with the levonorgestrel $20 \mathrm{mcg} / \mathrm{day}(\mathrm{LNg} 20)$ and the copper T $380 \mathrm{Ag}$ intrauterine devices: a five-year randomized study. Contraception. 1990;42:361-378.

69. Grimes DA, Hubacher D, Lopez LM, Schulz KF. Non-steroidal antiinflammatory drugs for heavy bleeding or pain associated with intrauterine-device use. Cochrane Database Syst Rev. 2006;CD006034.

70. Kurz KH, Tadesse E, Haspels AA. In vivo measurements of uterine cavities in 795 women of fertile age. Contraception. 1984;29:495-510.

71. Kulier R, Helmerhorst FM, O'Brien P, Usher-Patel M, d'Arcangues C. Copper containing, framed intra-uterine devices for contraception. Cochrane Database Syst Rev. 2006;3:CD005347.

72. Otero-Flores JB, Guerrero-Carreno FJ, Vazquez-Estrada LA. A comparative randomized study of three different IUDs in nulliparous Mexican women. Contraception. 2003;67:273-276.

73. Hov GG, Skjeldestad FE, Hilstad T. Use of IUD and subsequent fertility - follow-up after participation in a randomized clinical trial. Contraception. 2007;75:88-92.

74. Doll H, Vessey M, Painter R. Return of fertility in nulliparous women after discontinuation of the intrauterine device: comparison with women discontinuing other methods of contraception. BJOG. 2001;108:304-314.

75. Hubacher D, Lara-Ricalde R, Taylor DJ, Guerra-Infante F, Guzmán-Rodríguez R. Use of copper intrauterine devices and the risk of tubal infertility among nulligravid women. $N$ Engl $\mathrm{J} \mathrm{Med}$. 2001;345:561-567.

76. American College of Obstetricians and Gynecologists. ACOG Committee Opinion No. 392, December 2007. Intrauterine device and adolescents. Obstet Gynecol. 2007;110:1493-1495.

77. Deans El, Grines DA. Intrauterine devices for adolescents: a systematic review. Contraception. 2009;79:418-423.

78. Godfrey EM, Memmel LM, Neustadt A, et al. Intrauterine contraception for adolescents aged 14-18 years: a multicenter randomized pilot study of levonorgestrel-releasing intrauterine system compared to the Copper T 380A. Contraception. 2010;81:123-127.

79. Rivera R, Chen-Mok M, McMullen S. Analysis of client characteristics that may affect early discontinuation of the TCu-380A IUD. Contraception. 1999;60:155-160.

80. Zhang J, Feldblum PJ, Chi IC, Farr MG. Risk factors for copper T IUD expulsion: an epidemiologic analysis. Contraception. 1992; 46:427-433.

81. Cheng L, Gülmezoglu AM, Piaggio G, Ezcurra E, Van Look PF. Interventions for emergency contraception. Cochrane Database Syst Rev. 2000;CD001324.

82. Bilian X. Chinese experience with intrauterine devices. Contraception. 2007;75:S31-S34. 
83. Fasoli M, Parazzini F, Cecchetti G, La Vecchia C. Post-coital contraception: an overview of published studies. Contraception. 1989;39:459-468.

84. von Hertzen H, Piaggio G, Ding J, et al. Low dose mifepristone and two regimens of levonorgestrel for emergency contraception: a WHO multicentre randomised trial. Lancet. 2002;360:1803-1810.

85. Grimes D, Schulz K, Stanwood N. Immediate postabortal insertion of intrauterine devices. Cochrane Database Syst Rev. 2004; CD001777.

86. Grimes D, Schulz K, Stanwood N. Immediate postabortal insertion of intrauterine devices. Cochrane Database Syst Rev. 2002; CD001777.

87. Sivin I, Tatum HJ. Four years of experience with the TCu 380A intrauterine contraceptive device. Fertil Steril. 1981;36:159-163.

88. Walsh T, Grimes D, Frezieres R, et al. Randomised controlled trial of prophylactic antibiotics before insertion of intrauterine devices. IUD Study Group. Lancet. 1998;351:1005-1008.
89. Gillett PG, Lee NH, Yuzpe AA, Cerskus I. A comparison of the efficacy and acceptability of the Copper-7 intrauterine device following immediate or delayed insertion after first-trimester therapeutic abortion. Fertil Steril. 1980;34:121-124.

90. Kapp N, Curtis KM. Intrauterine device insertion during the postpartum period: a systematic review. Contraception. 2009;80:327-336.

91. Eroglu K, Akkuzu G, Vural G, et al. Comparison of efficacy and complications of IUD insertion in immediate postplacental/early postpartum period with interval period: 1 year follow-up. Contraception. 2006;74:376-381.

92. Lara Ricalde R, Menocal Tobias G, Ramos Pérez C, Velázquez Ramírez N. Random comparative study between intrauterine device Multiload Cu375 and TCu 380a inserted in the postpartum period. Ginecol Obstet Mex. 2006;74:306-311.

93. Grimes D, Schulz K, van Vliet H, Stanwood N. Immediate post-partum insertion of intrauterine devices: a Cochrane review. Hum Reprod. 2002;17:549-554.

\section{Publish your work in this journal}

The International Journal of Women's Health is an international, peerreviewed open-access journal publishing original research, reports, reviews and commentaries on all aspects of women's healthcare including gynecology, obstetrics, and breast cancer. Subject areas include: Chronic conditions (migraine headaches, arthritis, osteoporosis);

\section{Dovepress}

Endocrine and autoimmune syndromes; Sexual and reproductive health; Psychological and psychosocial conditions. The manuscript management system is completely online and includes a very quick and fair peer-review system. Visit http://www.dovepress.com/ testimonials.php to read real quotes from published authors. 